\title{
Penerapan Metode Smart Dalam Menentukan Obat Demam Terbaik Di Kota Pematangsiantar
}

\author{
Ahmad Maulana', Solikhun' ${ }^{2}$, Muhammad Ridwan Lubis ${ }^{3}$ \\ 1,2,3Sistem Informasi, STIKOM Tunas Bangsa, Pematangsiantar \\ email korespondensi :maulana7avanischen@gmail.com
}

\begin{abstract}
Absract- Fever is a condition when body temperature exceeds $37^{\circ} \mathrm{C}$ caused by disease or inflammation. And usually people from the lower middle class who have a fever, will look for a cure for fever in the nearest warung, pharmacy or minimarket. But still confused to know which brand of fever medicine is right. This study aims to help users of cold medicine brands in ranking which drug brand is the best. The method used in this research is Simple Multi Attribute Rating Technique. With this algorithm can optimize the problems that exist in my thesis assignment.
\end{abstract}

Keywords: Simple Multi Attribute Rating Technique, Fever Medicine

\begin{abstract}
Abstrak - Demam adalah suatu keadaan saat suhu badan melebihi $37^{\circ} \mathrm{C}$ yang disebabkan oleh penyakit atau peradangan. Dan biasanya orang - orang dari kalangan menengah kebawah yang terserang demam, akan mencari obat demam di warung, apotek ataupun minimarket terdekat. Namun masih bingung untuk mengetahui merk obat demam mana yang tepat. Penelitian ini bertujuan untuk membantu pengguna merk obat demam dalam merangking merk obat mana yang terbaik. Metode yang digunakan dalam penelitian ini yaitu Simple Multi Atribute Rating Technique. Dengan algoritma ini dapat mengoptimalkan permasalahan yang ada dalam tugas Skripsi saya.
\end{abstract}

Kata Kunci : Simple Multi Atribute Rating Technique, Obat Demam

\section{PENDAHULUAN}

Biasanya ketika seseorang terserang demam, hal yang dilakukan adalah mengkonsumsi obat - obatan yang biasa dijual di warung, mini market, apotek ataupun ditempat yang menjual obat - obatan sebagai tindakan awal. Dan banyak juga yang sudah membuat persediaan obat sebagai tindakan preventif. Ada banyak merk obat yang dipasarkan secara bebas dan harganya juga sangat terjangkau bagi kalangan menengah kebawah. Namun dengan banyaknya merk obat yang dipasarkan, membuat beberapa orang bingung harus memilih obat yang mana yang terbaik dan sesuai dengannya.

Menurut Penelitian Faizal, Agus Setyaningsih, \& Diponegoro (2017), "Implementasi Sistem Pendukung Keputusan dengan Metode SMART Untuk Merangking Kemiskinan Dalam Proses Penentuan Penerima Bantuan PKH”. Dalam penelitia ini metode SMART berhasil menyelesaikan masalah bantuan PKH dengan aeleksi penerima bantuan PKH dengan hasil 20 orang yang berhasil masuk dalam desil 1 dan 5 orang yang menjadi calon penerima bantuan PKH. Penulis menggunakan metode SMART (Simple Multi Atribute Rating Technique), diharapkan dapat memberikan rekomendasi terbaik untuk pengguna dalam menentukan pilihan obat demam terbaik dan melakukan perengkingan terhadap obat - obat demam tersebut. 


\section{METODE PENELITIAN}

\subsection{Metode Pengumpulan Data}

Dalam penelitian ini, pengumpulan data dilakukan dengan metode Sampling. Data obat demam dewasa yang diambil sebagai sampel sebanyak 30 data yang dipilih dari total 100 pengguna obat demam dewasa. Teknik yang digunakan dalam pengambilan data adalah: Pertama, Penelitian Kepustakaan (Library Research) yaitu penulis memanfaatkan perpustakaan elektronik sebagai sarana dalam mengumpulkan data, dengan membaca tulisan berupa buku elektonik dan jurnal elektronik yang berkaitan dengan kasus yang penulis angkat, Kedua, Penelitian Lapangan (Field Work Research) beberapa teknik penelitian yang penulis lakukan yaitu kuesioner. Hal ini penulis lakukan dengan memberikan kuesioner secara langsung kepada beberapa mahasiswa di STIKOM Tunas Bangsa sebagai data sample.

\subsection{Analisis Data}

Metode analisis data terdiri atas dua macam, yaitu metode statistik deskriptif dan metode statistik inferensial. Jika pada metode penelitian penulis menggunakan metode penelitian kuantitatif, maka metode analisis data yang penulis gunakan adalah metode statistik inferensial. Analisis statistik inferensial dapat dikatakan sebagai metode analisis dengan menggunakan data yang berbentuk angka dan dianalisis dengan cara membandingkan melalui perhitungan dan mengaplikasikannya dengan cara menggunakan rumus yang sesuai. Berikut adalah data kuesioner pemilihan obat demam terbaik:

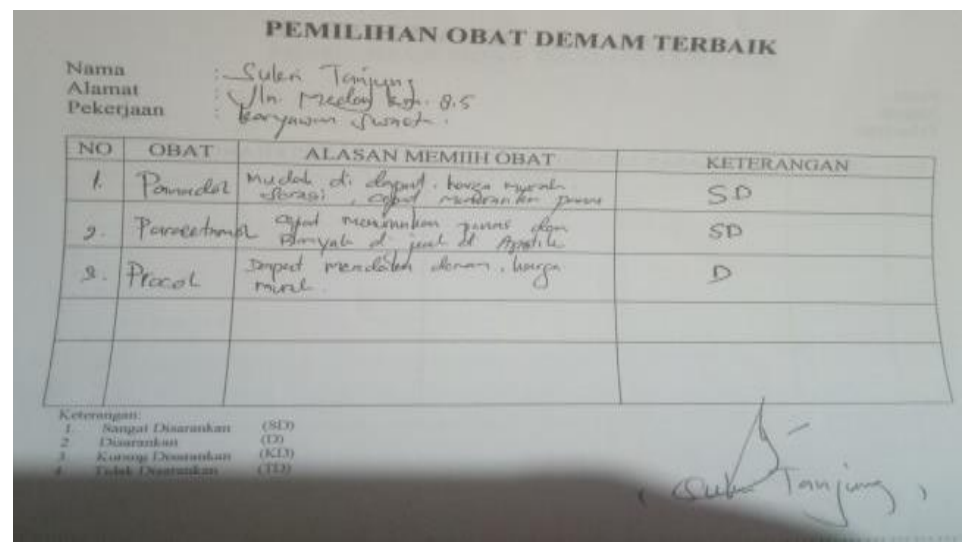

Gambar 1. Sample Kuesioner

Dari data tersebut penulis membuat kriteria dengan pembobotan sesuai dengan alasan pengguna obat demam dalam mengkonsumsi obat demam. Data kriteria yang digunakan dalam analisis penentuan obat demam terbaik dapat dilihat pada tabel 1 berikut :

Tabel 1. Data Kriteria

\begin{tabular}{|c|c|c|c|c|}
\hline \multirow[t]{2}{*}{ No } & \multirow{2}{*}{\multicolumn{2}{|c|}{ Kriteria }} & Bobot & Normalisasi \\
\hline & & & $(W \mathbf{j})$ & $\left(\mathrm{Wi}=\frac{W j}{\sum W j}\right)$ \\
\hline 1 & $\mathrm{C} 1$ & Harga & 50 & 0.5 \\
\hline 2 & C3 & Kandungan & 25 & 0.25 \\
\hline 3 & C4 & Efek Samping & 25 & 0.25 \\
\hline
\end{tabular}


Tabel 2. Hasil Rekomendasi

\begin{tabular}{|c|c|c|}
\hline No & Keterangan & Nilai \\
\hline 1 & Sangat Disarankan & $\geq 85$ \\
\hline 2 & Disarankan & $\geq 70$ \\
\hline 3 & Kurang Disarankan & $\geq 50$ \\
\hline 4 & Tidak Disarankan & $>50$ \\
\hline
\end{tabular}

Tabel 3. Sub Kriteria

\begin{tabular}{|c|c|c|c|}
\hline No & Kriteria & Sub Kriteria & Nilai \\
\hline \multirow{3}{*}{1} & \multirow{3}{*}{ Harga } & $\leq 3.000$ & 1 \\
\hline & & $\leq 5.000$ & 2 \\
\hline & & $\leq 8.000$ & 3 \\
\hline \multirow{4}{*}{2} & \multirow{4}{*}{ Kandungan } & Paracetamol & 1 \\
\hline & & phenylpropanolamine & 2 \\
\hline & & Chlorphenamine Maleate & 3 \\
\hline & & Caffeine & 4 \\
\hline \multirow{4}{*}{3} & \multirow{4}{*}{ Efek Samping } & Muncul Ruam & 1 \\
\hline & & Gangguan Pencernaan & 2 \\
\hline & & Kerusakan Fungsi Hati & 3 \\
\hline & & Penurunan Sel Darah Merah & 4 \\
\hline
\end{tabular}

Sebagai sampel penulis mengambil data dari hasil kuesioner 30 orang sebagai alternatif, dapat dilihat pada tabel 4 berikut :

Tabel 4. Data Alternatif Merk Obat Demam

\begin{tabular}{|c|c|c|}
\hline No & Alterntif & Nama Alternatif \\
\hline 1 & A1 & Bodrex \\
\hline 2 & A2 & Panadol \\
\hline 3 & A3 & Decolgen \\
\hline 4 & A4 & Mixagrip \\
\hline 5 & A5 & Parasetamol \\
\hline 6 & A6 & Procold \\
\hline
\end{tabular}

\subsection{Algoritma SMART}

Metode SMART merupakan metode pengambilan keputusan multi kriteria yang dikembangkan oleh Edward pada tahun 1977. SMART merupakan teknik pengambilan keputusan multi kriteria ini didasarkan pada teori bahwa setiap alternatif terdiri dari sejumlah kriteria yang memiliki nilai-nilai dan setiap kriteria memiliki bobot yang menggambarkan seberapa penting ia dibandingkan dengan kriteria lain

$$
\operatorname{SMART}=\sum_{j=1}^{k} w_{j} u_{i j}
$$

Dimana :

$\mathrm{W}_{\mathrm{j}} \quad=$ nilai pembobotan kriteria ke-j dari k kriteria

$\mathrm{U}_{\mathrm{ij}} \quad$ = nilai utility $\mathrm{i}$ pada kriteria $\mathrm{j}$

Pemilihan keputusan adalah mengidentifikasi mana dari $\mathrm{n}$ alternative yang mempunyai nilai fungsiterbesar

Nilai fungsi ini juga dapat digunakan untuk merangking $n$ alternatif 
Menghitung nilai normalisasi bobot :

$$
n w_{j}=\frac{w_{j}}{\sum_{n=1}^{k} w_{n}}
$$

Dimana:

$$
\begin{array}{ll}
n w_{j} & =\text { normalisasi bobot kriteria ke- } \mathrm{j} \\
w_{j} & =\text { nilai bobot kriteria ke- } \mathrm{j} \\
\mathrm{k} & =\text { jumlah kriteria } \\
w_{n} & =\text { bobot kriteria ke- } \mathrm{n}
\end{array}
$$

Menghitung nilai utiliti:

$$
u_{i j}=f\left(v_{i j}\right)
$$

Dimana :

$u_{i j} \quad=$ nilai utiliti kriteria ke- $\mathrm{j}$ untuk alternatif $\mathrm{i}$

$v_{i j} \quad=$ nilai kriteria ke- $\mathrm{j}$ untuk alternatif $\mathrm{i}$

$\mathrm{F}\left(v_{i j}\right)=$ fungsi kriteria ke- $\mathrm{j}$ untuk alternatif $\mathrm{i}$

\subsection{Adobe Dreamweaver CS6}

Adobe Dreamweaver CS6 adalah perangkat lunak bebas untuk tujuan akademik dan penelitian. Pada penelitian ini aplikasi ini memungkinkan menciptakan sebuah website dari yang sederhana hingga yang paling rumit sekalipun.

\section{HASIL DAN PEMBAHASAN}

\subsection{Perhitungan Algoritma SMART}

Sebelum memasuki tahap perhitungan dengan algoritma SMART (Simple Multi Attribute Rating Technique), penulis terlebih dahulu membuat rating kecocokan alternatif terhadap kriteria, dari data nilai alternatif yang penulis dapatkan dari hasil wawancara yang penulis lakukan sebelumnya. Berikut adalah tabel nilai alternatif untuk setiap kriteria :

Tabel 5. Nilai Alternatif

\begin{tabular}{|c|c|c|c|}
\hline Alternatif & \multicolumn{3}{|c|}{ Tingkat Rekomendasi } \\
\hline Merk Obat Demam & C1 & C2 & C3 \\
\hline Bodrex & 3 & 3 & 2 \\
\hline Panadol & 3 & 2 & 4 \\
\hline Decolgen & 1 & 3 & 3 \\
\hline Mixagrip & 1 & 1 & 2 \\
\hline Paracetamol & 2 & 4 & 1 \\
\hline Procold & 2 & 3 & 2 \\
\hline
\end{tabular}

Setelah keseluruhan data yang diperlukan seperti kriteria, bobot kriteria, sampel alternatif, serta rating kecocokan alternatif terhadap kriteria telah tersedia, maka langkah selanjutnya adalah melakukan perhitungan dengan menggunakan algoritma SMART yaitu menghitung nilai utility untuk masing masinng kriteria :

$V_{i}(a i)=100 \frac{(\text { max }- \text { cout } i)}{(\text { cmax }- \text { cmin })}$ 
Tabel 6. Penilaian Harga

\begin{tabular}{|c|c|c|}
\hline Penilaian Responden & Nilai & $\boldsymbol{U}_{\boldsymbol{i}}(\boldsymbol{a i})$ \\
\hline A1 & 3 & $100 \frac{(5-1)}{(5-3)}=200$ \\
\hline A2 & 3 & $100 \frac{(5-1)}{(5-3)}=200$ \\
\hline A3 & 1 & $100 \frac{(5-1)}{(5-3)}=100$ \\
\hline A4 & 1 & $100 \frac{(5-1)}{(5-3)}=100$ \\
\hline A5 & 2 & $100 \frac{(5-1)}{(5-3)}=133.33$ \\
\hline A6 & 2 & $100 \frac{(5-1)}{(5-3)}=133.33$ \\
\hline
\end{tabular}

Tabel 7. Nilai Akhir Harga

\begin{tabular}{|c|c|c|c|c|c|}
\hline \multirow{2}{*}{ Kategori } & \multirow{2}{*}{$\boldsymbol{U}_{\boldsymbol{i}}(\boldsymbol{a i})$} & \multicolumn{3}{|c|}{$\boldsymbol{W} \boldsymbol{j}$} & \multirow{2}{*}{ Total $\sum \boldsymbol{n a}$} \\
\cline { 3 - 6 } & 200 & $\mathbf{0 . 5}$ & $\mathbf{0 . 2 5}$ & $\mathbf{0 . 2 5}$ & \\
\hline $\mathrm{A} 1$ & 100 & 50 & 50 & 200 \\
\hline $\mathrm{A} 2$ & 200 & 100 & 50 & 50 & 200 \\
\hline $\mathrm{A} 3$ & 100 & 50 & 25 & 25 & 100 \\
\hline $\mathrm{A} 4$ & 100 & 50 & 25 & 25 & 100 \\
\hline $\mathrm{A} 5$ & 133.33 & 66.665 & 33.33 & 33.33 & 133.33 \\
\hline A6 & 133.33 & 66.665 & 33.33 & 33.33 & 133.33 \\
\hline
\end{tabular}

Tabel 8. Penilaian Kandungan

\begin{tabular}{|c|c|c|}
\hline Penilaian Responden & Nilai & $\boldsymbol{U}_{\boldsymbol{i}}(\boldsymbol{a} \boldsymbol{i})$ \\
\hline A1 & 3 & $100 \frac{(5-1)}{(5-3)}=200$ \\
\hline A2 & 2 & $100 \frac{(5-1)}{(5-2)}=133.33$ \\
\hline A3 & 3 & $100 \frac{(5-1)}{(5-3)}=200$ \\
\hline A4 & 1 & $100 \frac{(5-1)}{(5-1)}=100$ \\
\hline A5 & 4 & $100 \frac{(5-1)}{(5-4)}=400$ \\
\hline A6 & 3 & $100 \frac{(5-1)}{(5-3)}=200$ \\
\hline
\end{tabular}

Tabel 9. Nilai Akhir Kandungan

\begin{tabular}{|c|c|c|c|c|c|}
\hline \multirow{2}{*}{ Kategori } & \multirow{2}{*}{$\boldsymbol{U}_{\boldsymbol{i}}(\boldsymbol{a i})$} & \multicolumn{3}{|c|}{$\boldsymbol{W j}$} & \multirow{2}{*}{ Total $\sum \boldsymbol{n a}$} \\
\cline { 3 - 6 } & 200 & 100 & 50 & 50 & 200 \\
\hline A1 & 200 & $\mathbf{0 . 2 5}$ & $\mathbf{0 . 2 5}$ & \\
\hline A2 & 133.33 & 66.66 & 33.33 & 33.33 & 133.33 \\
\hline A3 & 200 & 100 & 50 & 50 & 200 \\
\hline A4 & 100 & 50 & 25 & 25 & 100 \\
\hline A5 & 400 & 200 & 100 & 100 & 400 \\
\hline A6 & 200 & 100 & 50 & 50 & 200 \\
\hline
\end{tabular}

Tabel 10. Penilaian Efek Samping

\begin{tabular}{|c|c|c|}
\hline Penilaian Responden & Nilai & $\boldsymbol{U}_{\boldsymbol{i}}(\boldsymbol{a} \boldsymbol{i})$ \\
\hline A1 & 1 & $100 \frac{(4-1)}{(4-1)}=100$ \\
\hline A2 & 2 & $100 \frac{(4-1)}{(4-2)}=66.6$ \\
\hline A3 & 1 & $100 \frac{(4-1)}{(4-4)}=100$ \\
\hline A4 & 2 & $100 \frac{(4-1)}{(4-1)}=66.6$ \\
\hline A5 & 3 & $100 \frac{(4-2)}{(4-4)}=33.3$ \\
\hline
\end{tabular}


Tabel 11. Nilai Akhir Efek Samping

\begin{tabular}{|c|c|c|c|c|c|}
\hline \multirow{2}{*}{ Kategori } & \multirow{2}{*}{$\boldsymbol{U}_{\boldsymbol{i}}(\boldsymbol{a} \boldsymbol{a})$} & \multicolumn{3}{|c|}{$\boldsymbol{W j}$} & Total \\
\cline { 3 - 5 } & 100 & $\mathbf{0 . 5}$ & $\mathbf{0 . 2 5}$ & $\mathbf{0 . 2 5}$ & $\sum \boldsymbol{n a}$ \\
\hline $\mathrm{A} 1$ & 100 & 25 & 25 & 100 \\
\hline $\mathrm{A} 2$ & 66.6 & 33.3 & 16.65 & 16.65 & 66.6 \\
\hline $\mathrm{A} 3$ & 100 & 50 & 25 & 25 & 100 \\
\hline $\mathrm{A} 4$ & 66.6 & 33.3 & 16.65 & 16.65 & 66.6 \\
\hline $\mathrm{A} 5$ & 33.3 & 16.65 & 8.325 & 8.325 & 33.3 \\
\hline
\end{tabular}

Dari perhitungan tersebut diperoleh hasil seperti pada tabel berikut :

Tabel 12. Rangking Untuk Alternatif

\begin{tabular}{|c|c|c|}
\hline Nama Alternatif & $\sum \boldsymbol{n a}$ & Ranking \\
\hline Bodrex & 183.33 & 4 \\
\hline Panadol & 233.33 & 6 \\
\hline Decolgen & 150 & 3 \\
\hline Mixagrip & 108.33 & 1 \\
\hline Paracetamol & 191.66 & 5 \\
\hline Procold & 149.99 & 2 \\
\hline
\end{tabular}

\subsection{Perhitungan Algoritma SMART Berbasis Web}

Setelah melakukan tahap analisis dan perhitungan manual, langkah selanjutnya adalah tahap pengujian berbasis Web.

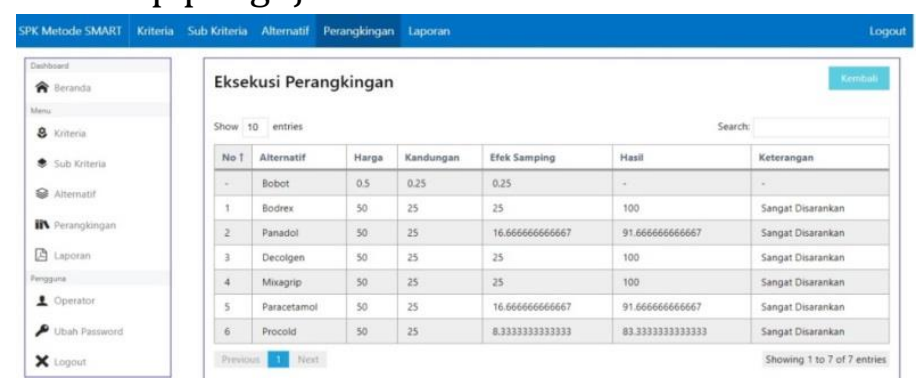

Gambar 2. Tampilan Hasil Perengkingan

Berdasarkan hasil akhir yang diperoleh, didapatlah alternatif Mixagrip menempati rangking pertama dengan nilai 108.33, Procold menempati ranking kedua dengan nilai 149.99, Decolgen menempati rangking ketiga dengan nilai150, Bodrex menempati ranking keempat dengan nilai 183.33, Paracetamol menempati rangking kelima dengan nilai 191.66 dan Panadol menempati ranking terakhir dengan nilai 233.33. Sehinggal alternative - alternative ini menjadi rekomendasi dalam memilih obat demam terbaik di Kota Pematangsiantar dengan menggunakan metode SMART.

\section{SIMPULAN}

Berdasarkan hasil penelitian yang dilakukan dengan menggunakan metodologi penelitian yang digunakan maka dapat disimpulkan bahwa

a. Sistem yang dibangun menggunakan algoritma SMART (Simple Multi Attribute Rating Technique) dalam menentukan obat demam terbaik di Kota Pematangsiantar 
b. Memberikan rekomendasi obat demam yang sesuai dengan penggunanya. Namun tetap keputusan akhir ada pada pengguna

Adapun saran yang dapat penulis sampaikan untuk penelitian lebih lanjut yaitu, Kepada peneliti yang berikutnya dan ingin melanjutkan penelitian ini diharapkan nantinya dapat mengembangkan alternative dan objek penelitian tambahan sehingga dapat memberikan rekomendasi yang lebih baik lagi karena penelitian yang dirancang masih bersfat sederhana dan masih memiliki kekurangan

\section{DAFTAR PUSTAKA}

[1] Bartolomius, H., \& Palupi, S. (2015). Sistem Pendukung Keputusan Penerimaan Asisten Laboratorium Komputer Menggunakan Metode Simple Additive Weighting (Studi Kasus Pada Laboratorium Komputer STMIK Widya Cipta Dharma Samarinda). Prosiding Seminar Ilmiah Nasional Teknologi Komputer (SENATKOM 2015), 1(Senatkom), 90-95.

[2] Diaz, D. C. P., Sulistiowati, \& Lemantara, J. (2016). Rancang Bangun Aplikasi Penjualan Online pada CV. Mitra Techno Sains (Studi Kasus: CV. Mitra Techno Sains). JSIKA, 5(12), 1-7.

[3] Faizal, Agus Setyaningsih, F., \& Diponegoro, M. (2017). Implementasi Sistem Pendukung Keputusan Dengan Metode SMART Untuk merangking Kemiskinan Dalam proses Penentuan Penerima Bantuan PKH. Coding Jurnal Komputer Dan Aplikasi Untan, 05(2), 13-24.

[4] Halim, A. (2016). Penerapan Metode Smart Dalam Sistem Pendukung Keputusan Menentukan Pemenang Tender Proyek Pada Dinas Pekerja Umum Kota Medan.

[5] Iriane, G. R., Ernwati, \& Wisnubhadra, I. (2013). Analisis penggabungan metode saw dan metode topsis untuk mendukung keputusan seleksi penerimaan dosen. Seminar Nasional Informatika 2013 (SemnasIf 2013), 2013(semnasIF), 1-7.

[6] Khoirunnissa, R., Isnanto, R. R., \& Martono, K. T. (2016). Pembuatan Aplikasi Web Manajemen Laundry dan Integrasi Data dengan Web Service. Jurnal Teknologi Dan Sistem Komputer, 4(1), 93-101.

[7] Mallu, S. (2015). Sistem pendukung keputusan penentuan karyawan kontrak menjadi karyawan tetap menggunakan metode topsis. Jurnal Ilmiah Teknologi Informasi Terapan (JITTER), I(2), 36-42.

[8] Ria, S., Siregar, S., \& Sundari, P. (2016). Rancangan Sistem Informasi Pengelolaan Data Kependudukan Desa ( Studi Kasus di Kantor Desa Sangiang Kecamatan Sepatan Timur ). JURNAL SISFOTEK GLOBAL, 6(1).

[9] Safrizal, M. (2015). Sistem Pendukung Keputusan Pemilihan Karyawan Teladan dengan Metode SMART (Simple Multi Attribute Rating Technique). Jurnal CoreIT, 1(2), 2460-2738.

[10] Santoso, \& Yuliyanti, W. (2016). Perencanaan Dan Pembuatan Aplikasi Absensi Dosen Menggunakan Radio Frequency Identification ( RFID ) ( Studi Kasus Politeknik Negeri Tanah Laut ). SEMINAR NASIONAL INOVASI DAN APLIKASI TEKNOLOGI DI INDUSTRI (SENIATI), 332-337.

[11] Suripto, M. A. S., \& Triyono, R. A. (2014). Pembangunan Sistem Informasi Akta Kelahiran. Indonesian Journal on Networking and Security, 3(3), 33-40.

[12] Syarif, A., Jurusan, D., Informatika, T., Teknologi, F., Teknik, M., Fakultas, I., \& Industri, T. (2016). Jurnal TEKNOIF ISSN : 2338-2724 SISTEM INFORMASI GEOGRAFIS SARANA PADA Jurnal TEKNOIF ISSN : 2338-2724, 4(2), 40-50.

[13] Tumenggung, I. (2013). Journal of Nursing and Public Health. Jurnal Kesehatan Politeknik Kesehatan Gorontalo, 9(16), 100-105. 
[14] Widodo, M. R. R., Zainuddin, M. R., \& Nusantara, L. S. (2016). Sistem Informasi Dan Pengolahan Data Kursus Mobil Berbasis Web Dengan Sms. JIMP - Jurnal Informatika Merdeka Pasuruan, 1(3), 85-104. 